\title{
Urban exposure: training activities and risk reduction
}

\author{
F. Russo \& C. Rindone \\ DIIES - Dipartimento di ingegneria dell'Informazione, \\ delle Infrastrutture e dell'Energia Sostenibile, \\ Università degli Studi Mediterranea di Reggio Calabria, Italy
}

\begin{abstract}
The purpose of this paper is to analyse training activities implemented to reduce risks related to natural or man-made dangerous events in an urban area. Evacuation contributes to reduce the exposure risk component; training activities and, in particular, exercises to test evacuation are focused. The principal aim of this work is to evaluate exposure risk reduction connected with the realization of specific training activities.

Keywords: disaster risk reduction, exposure, evacuation, risk analysis, training, performance.
\end{abstract}

\section{Introduction}

The United Nations indicate that over the last twenty years, it is conservatively estimated that disasters have killed 1.3 million people, affected 4.4 billion and resulted in economic losses of $\$ 2$ trillion. These are costs measures of inaction on climate change and risk reduction [1]. In 2005, at the World Conference on Disaster Reduction, 168 United Nations member states adopted the Hyogo Framework for Action 2005-2015: Building the Resilience of Nations and Communities to Disasters. In this context, the United Nations have adopted an International Strategy for Disaster Reduction (ISDR) to analyse and to reduce risk disasters [2].

In literature risk has three main components: the occurrence of a disastrous event, measured in terms of probability or frequency of a specific event actually happening; vulnerability, related to the resistance of the infrastructures when the event occurs; exposure, related to the equivalent homogeneous weighted value of 
people, goods and infrastructures affected during and after the event [3]. This paper focus on exposure risk component. The main macro-action to reduce exposure is evacuation, which consists in reducing the number of users and goods that can experience negative effects when emergency events occur. Effective evacuation depends on several factors such as warning time, response time, information and instructions dissemination procedure, evacuation routes, traffic flow conditions, dynamic traffic control measures, and others [4]. These factors influence people's behavior during an emergency situation. A possible classification of exogenous activities comprehends [5]: activities related to material infrastructures (e. g. interventions on physical characteristics); nonmaterial activities (e. g. interventions on learning and training or on Intelligent Transportation Systems); activities related to equipment (e. g. interventions to acquire tools and specific transport vehicles); management activities (e.g. interventions to design transportation services); governance and institutional activities (e.g. interventions to regulate the transportation system). In this paper we focus on non-material activities and in particular on training that comprehend discussion - based and operation-based exercises [6]. In the following these class of activities is indicated how training activities.

Training activities increase level of preparedness comprehending simulation of an emergency situation [7].

Formal education and previous experiences with disasters increase disaster preparedness. Muttarak and Pothisiri [8] evidence that education has a relationship with disaster preparedness. Two classes of variables are included in an empirical analysis: the first class is related to education level, measured at the individual, household, and community levels; the second class is related to disaster-related variables associated with disaster preparedness (e.g. participation in tsunami drills and disaster education). Education enhances individual cognitive and learning skills, as well as access to information. Household, with previous disaster experience, and highly educated members, are better prepared for the disasters.

Training activities have different characteristics and different aims. An effective training action has to designed, implemented and evaluated during and after execution. The evaluation contribute to improve emergency planning. Evaluation of discussion-based exercises focus on analyses of plans adequacy; resources; capabilities of people involved. Evaluation of operations-based exercises focus on areas such as effectiveness of communications, of management, adequacy of equipment and of cooperation among all actors involved in operations [9].

Training activities are designed, implemented and evaluated to: validate emergency plans; to train decision makers and staff; to test emergency procedures. In literature there is research to evaluate how training activities contribute to increase level of preparedness personnel involved in emergency situations.

However, there are no studies to quantify the reduction of exposure risk component in relation to quantified training activities implementation.

In this paper training activities, supporting evacuation planning in an urban area, are focused. These activities, involving principal stakeholders of emergency, are useful tools to test the plans, the operative organization and the public answers, 
on a regular basis and measure preparedness efforts. Principal aim of this paper is to propose a method to measure how training activities contribute to reduce exposure risk component, in a quantified value.

The paper, after this introduction, has two sections. In section 2 an analysis of training experiences in Europe and in USA, in the context of urban evacuation, is presented. These experiences regard the exercises for which one or more targets for training actions are introduced as reference levels. In some actions a measure systems relative to the distance to the target are introduced. In section 3, a method to evaluate exercises is proposed. The evaluation of results is quantified in the scale of the risk reduction quantity.

\section{Training experiences for evacuation planning}

\subsection{USA experiences}

In the USA, after domestic terroristic attacks in 1993, 1995, and 2001, the Department of Homeland Security (DHS) has spent much effort to prepare for, prevent, respond to, and recover from a variety of threats to public safety. In the preparedness context, training activities play a relevant role. In particular exercises provide opportunities to practice and to assess collective capabilities in emergency management. For this purpose, DHS, and in particular the National Preparedness Directorate (NPD), has developed the Homeland Security Exercise and Evaluation Program (HSEEP). This is a multiannual exercise program to support exercise design, development, conduct, evaluation, and improvement planning [9]. In the context of HSEEP, an Exercise Evaluation Guide has published to provide a tool for guiding exercise observation and data collection. The guide it is useful to verify the coherence of exercises with capability targets and critical tasks according to national planning and in particular with National Preparedness Goal [10, 11].

In Figure 1 the USA training activities classification [12], with specific reference to exercises, is presented.

The US Federal Emergency Management Agency (FEMA) has introduced the Threat and Hazard Identification and Risk Assessment (THIRA) that standardizes the risk analysis process to support communities in identifying risks and setting capability targets for each core capability identified in the National Preparedness Goal. Outputs of the four steps THIRA process include: the specific and measurable targets, developed considering impacts and desired outcomes for each threat and hazard; the resources needed to meet the capability targets [13].

\subsection{European Union experiences}

The European Civil Protection (ECP), in 2001 has established the Civil Protection Mechanism (CPM) to support and to facilitate cooperation between Community and the Member States in civil protection assistance intervention in the event of major emergencies [14]. European emergency assistance may be required in all of those disasters to complement the response capabilities of the affected country. In 2012, CPM was activated 38 times: 16 activations concerned countries that operate 
within the EU CPM; 22 concerned countries elsewhere [15]. In this context the European Commission supports disaster preparedness and prevention activities within the EU. Principal activities comprehend: training of civil protection personnel; large-scale simulation exercises; exchange of experts; cooperation projects on prevention and preparedness, involving actors from two or more Member States $[15,16]$.

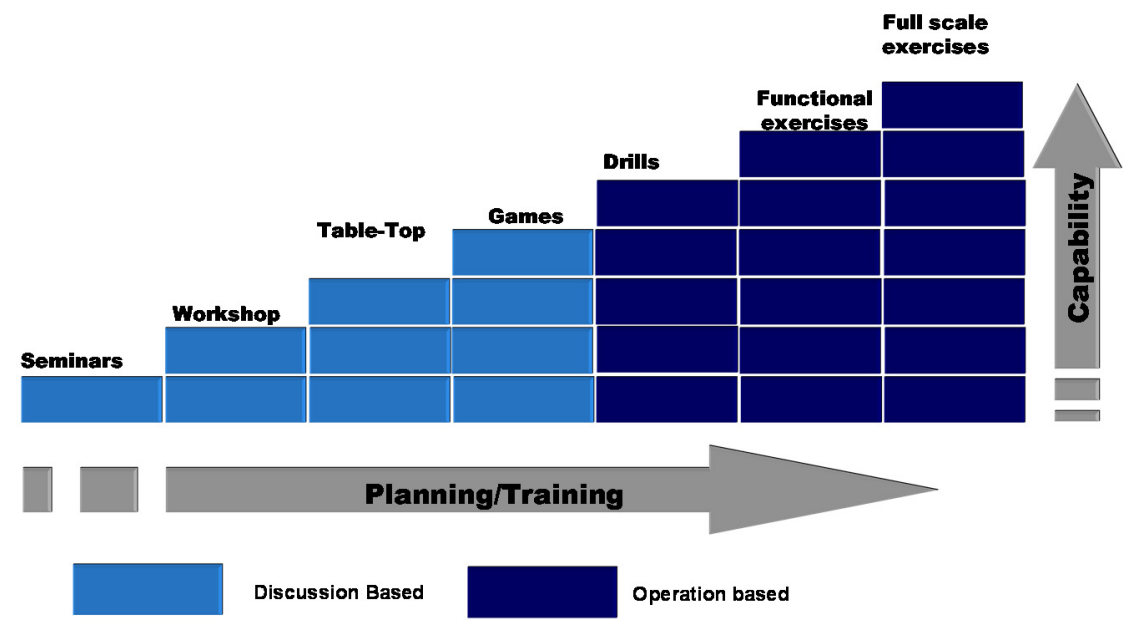

Figure 1: USA training activities classification (source: [12]).

In 2013, European Union has adopted the new Union Civil Protection Mechanism (Union Mechanism) to improve the effectiveness of systems preventing, preparing for and responding to natural and man-made disasters of all kinds within and outside the EU. The new mechanism focus on disaster prevention, with provisions relating to risk assessment and risk management planning. The principal aim is to ensure an integrated approach to disaster management, linking risk prevention, preparedness and response actions. The Union Mechanism should include a general policy framework aimed at continuously improving the level of preparedness of civil protection systems, services, their personnel and population within the Union. This should include a programme of exercises, a programme of lessons learnt as well as training programmes and a training network, at Union and Member State level, on prevention of, preparedness for and response to disasters [17]. To implement the Union Mechanism, the EU allocate about 368,4 MEuro for the period 2014 to 2020. The 2014 Work Programme (WP 2014) has adopted to finance prevention and preparedness projects [18]. In the WP 2014, specific actions to develop exercises are financed. In particular, the action 2.8 finances the European civil protection mechanism exercises. The principal objective is to improve civil protection preparedness and response to all kinds of disasters. In order to achieve the objectives, different types of European exercises are defined: 
- Table-Top Exercise (TTEX) designed to put real crisis managers in a situation to use existing plans and procedures to take decisions according to a proposed scenario, or other types of discussion based exercises;

- Command Post Exercises (CPEX) with limited deployment, designed to put command structures in a real situation;

- Full Scale Exercises (FSE), designed to replicate one or several phases of an emergency with the commitment of all the public bodies and authorities that would be committed in a real situation [19].

In Figure 2 the European training activities classification, with specific reference to exercises, is presented.

Implementing exercises it is possible to test and train modules of EU Civil Protection in order to increase preparedness level in the framework of the ECPM.

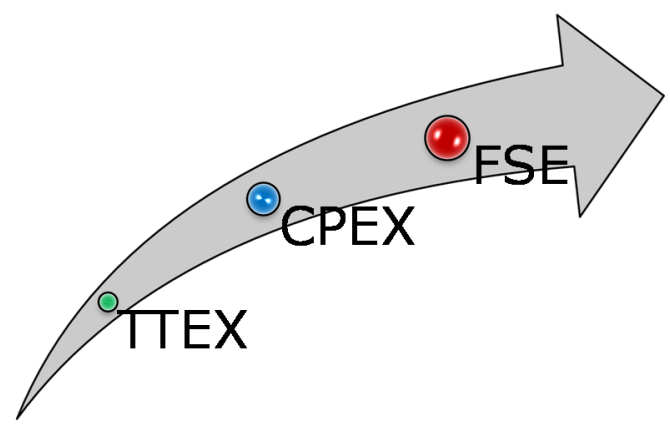

Figure 2: $\quad$ European training activities classification [21].

\subsection{Problem definition}

From the presented experiences, it emerges that training activities are aimed to increase level of preparedness of emergency operators. In particular, exercises are implemented to test operations that civil protection organizations should implement during an emergency situation (decision-making procedures, provision of information to the public and the media, humanitarian logistics, ...). Generally, principal aim of training activities is to reduce the response time to emergencies. Exercises can support decision makers to improve training needs and operational gaps. Exercises verify the level of preparedness of organizations for similar reallife emergency situations.

However, there is no a method to measure how a generic training action contributes to reduce risk level, both societal an individual. Considering the societal risk, there is no function for estimating the quantity of risk reduction that is possible to obtain in relation to a single or multiple training activities.

In this paper, in the context of urban evacuation and in relation to training activities, a method to estimate quantity of exposure reduction is proposed. The method is aimed to estimate exposure and their modification in relation to 
execution of a specific training action, in the context of urban evacuation. In the following it is considered only the aspect relative to transport system.

\section{Exposure reduction in relation to training activities}

In relation to a disastrous event, considering the societal risk and fixing occurrence and vulnerability levels, it is possible to estimate the exposure quantity of an urban area. To reduce the exposure, in presence of an event, evacuation procedures must be activated. By means of evacuation, the societal risk is reduced. The quantity of reduction can be estimated in two ways adopting:

- modeling methods that consist on simulation of transport system in evacuation conditions adopting a set of models that comprehends:

○ transport demand models to simulate mobility choices [22];

○ supply models to simulate available transport infrastructure and services during an evacuation [23];

○ transport supply-demand interaction models in relation to route choices and then the estimation of urban network flows [24];

- monitoring methods that consist of implementation of an evacuation that is monitored to acquire quantitative information about exposure quantity reduction.

It is possible, in a theoretical way, to estimate, for each training action, two different risk levels:

- a before quantity risk level that correspond to an emergency scenario, defined in terms of event occurrence and vulnerability, for which the evacuation training action considered has not been implemented;

- an after quantity of risk level that correspond to an emergency scenario in which the evacuation training action has been implemented.

The two quantities are used to estimate the contribution of a specific training action to risk reduction.

Developing more experiments with the same action in different urban contexts, it could be possible to build a relation to obtain modelling methods to calculate the reduction in similar contexts.

\subsection{Quantity indicators of risk level}

At the time when the study of the evacuation plan originates, assuming fixed level of occurrence and vulnerability for a defined event, to obtain the initial quantity of risk level it is necessary to estimate exposure. It is possible to realize an exercise to simulate an evacuation in a real context (evacuation exercise) in relation to the urban evacuation plan, if it is available. In this plan, in relation to the simulated disastrous event, instructions to implement an evacuation are included. Descriptions of actions that people have to realize during an evacuation are included, for instance: safe areas to reach; transport modes to use; evacuation routes to follow. 
At the initial situation, any evacuation planning action has been implemented. Then, stakeholders (decision makers; emergency operators; people) have a lack of knowledge for realizing an optimal evacuation.

In the generic scenario $s$, referring to a generic disastrous event for which occurrence $\left(\mathrm{O}^{\mathrm{s}}\right)$ and vulnerability $\left(\mathrm{V}^{\mathrm{s}}\right)$ are known, the risk level $\left(\mathrm{R}^{\mathrm{s}}\right)$ depend only to the exposure level $\mathrm{E}^{\mathrm{s}}[3,25]$ :

$$
\mathrm{R}^{\mathrm{s}}=\mathrm{O}^{\mathrm{s}} \cdot \mathrm{V}^{\mathrm{s}} \cdot \mathrm{E}^{\mathrm{s}}
$$

Adopting monitoring methods, it is possible to estimate $m$ exposure indicators that can be organised in a vector:

$$
\mathbf{e}^{\mathrm{s}}=\left(\mathrm{e}^{\mathrm{s}}, \mathrm{e}^{\mathrm{s}}, \ldots, \mathrm{e}_{\mathrm{m}}^{\mathrm{s}}\right)
$$

from which the exposure can be calculated:

$$
\mathrm{E}^{\mathrm{s}}=f\left(\mathbf{e}^{\mathrm{s}}\right)
$$

where

$f(\cdot) \quad$ is the exposure function defined in relation to the scenario $\mathrm{s}$ and indicators $\mathbf{e}^{\mathbf{s}}$.

In the aggregate approach to societal risk, the common related measures are given by frequencies (F) and Fatalities (N). An example of F-N curve adopted in Quantitative Risk Analysis is reported in Figure 3 [25].

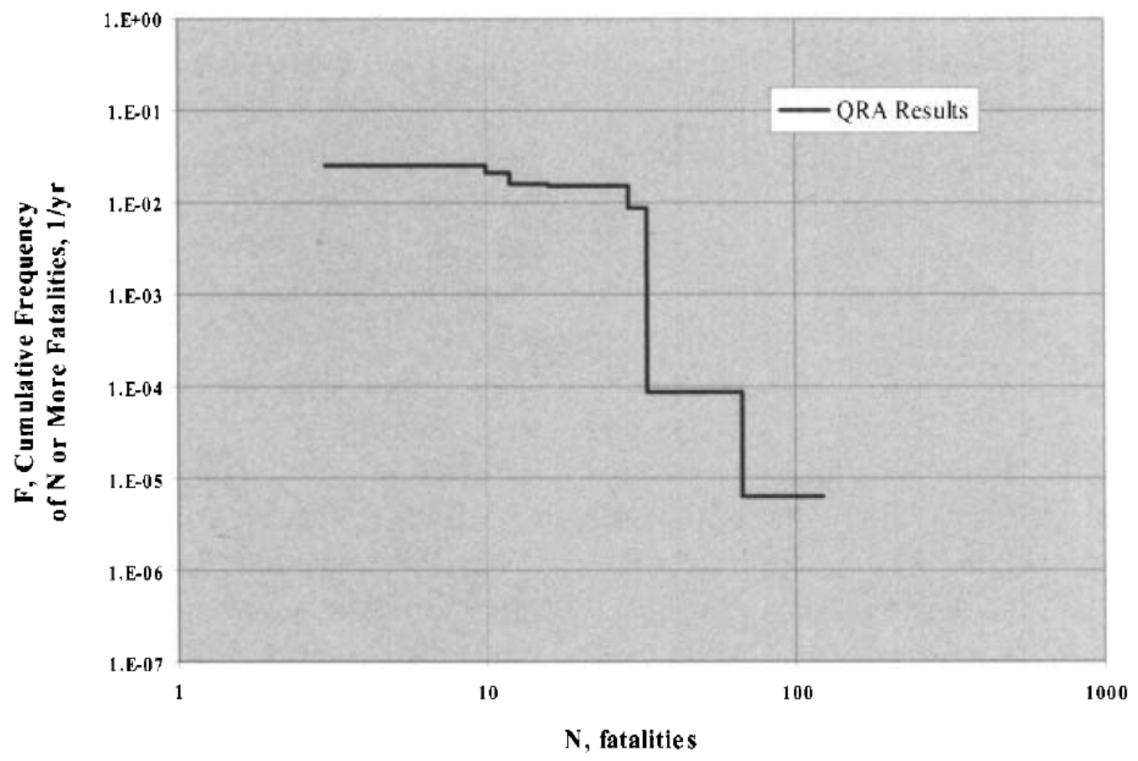

Figure 3: Example of F-N curve [25]. 


\subsection{Risk reduction related to a training action}

Risk reduction related to training activities could be estimated adopting monitoring methods.

Defining a specific event, the following hypothesis are introduced:

- occurrence $\left(\mathrm{O}^{\mathrm{s}}\right)$ and vulnerability $\left(\mathrm{V}^{\mathrm{s}}\right)$ values are equal to initial values and are constant; risk reduction is related to only exposure quantity;

- results from different actions implementations are independent.

The set of event, occurrence and vulnerability is defined base scenario. With this definition the risk in the generic base scenario $s$ can be different only in relation to the exposure.

In relation to a generic $s$, a set of $n$ training actions to reduce exposure risk can be implemented. Indicators of quantities, related to each action implemented, can be organized in the following vector:

$$
\mathbf{a}^{\mathrm{s}}=\left(\mathrm{a}_{1}^{\mathrm{s}}, \mathrm{a}_{2}^{\mathrm{s}}, \ldots, \mathrm{a}_{\left.\mathrm{k}, \ldots, \mathrm{a}_{\mathrm{n}}^{\mathrm{s}}\right)}^{\mathrm{s}}\right.
$$

where $\mathrm{a}_{\mathrm{k}}^{\mathrm{s}}$ is the generic $k$ training action.

Each action $\mathrm{a}_{\mathrm{k}}^{\mathrm{s}}$ contributes to reduce exposure in the scenario $s$. It is possible to specify the vector $\mathbf{e}^{\mathbf{s}}$ before and after the implementation of $\mathbf{a}^{\mathbf{s}}$ :

$$
\mathbf{e}^{\mathbf{s}}=g\left(\mathbf{a}^{\mathbf{s}}\right)
$$

where $g(\cdot)$ is the function of exposure in relation to training actions in scenario s.

If it is used the hypothesis of independency of results, before the implementation of action $\mathrm{a}_{\mathrm{k}}{ }^{\mathrm{s}}$, the before exposure level is:

where

$$
\mathrm{E}_{\text {before }}^{\mathrm{s}}=f\left(\mathbf{e}_{\text {before }}^{\mathrm{s}_{\text {e }}}\right)=f\left(g\left(\alpha_{1}^{\mathrm{s}}, \alpha_{2}^{\mathrm{s}}, \ldots, \mathrm{a}_{\mathrm{k}}^{\mathrm{s}}=0, \ldots, \alpha_{\mathrm{n}}^{\mathrm{s}}\right)\right)
$$

$\alpha_{\mathrm{i} \neq \mathrm{k}}^{\mathrm{s}}, \quad$ are quantities values relative to actions different from $\mathrm{a}_{\mathrm{k}}^{\mathrm{s}}$, constant before and after $a_{k}{ }^{s}$.

With the same hypothesis it is possible to define the after exposure level:

$$
\mathrm{E}_{\mathrm{after}}^{\mathrm{s}}=f\left(\mathbf{e}_{\mathrm{after}}^{\mathrm{s}_{\mathrm{f}}}\right)=f\left(g\left(\alpha_{1}^{\mathrm{s}}, \alpha_{2}^{\mathrm{s}}, \ldots, \mathrm{a}_{\mathrm{k}}^{\mathrm{s}} \neq 0, \ldots, \alpha_{\mathrm{n}}^{\mathrm{s}}\right)\right)
$$

Then the exposure quantity reduction in relation to the implementation of $\mathrm{a}^{\mathrm{s}} \mathrm{k}$ is:

$$
\Delta \mathrm{E}_{\mathrm{k}}^{\mathrm{s}}=\mathrm{E}_{\mathrm{after}}^{\mathrm{s}}-\mathrm{E}_{\text {before }}^{\mathrm{s}}
$$

To calibrate the functions $f(\cdot)$ and $g(\cdot)$, monitoring methods, before and after $\mathrm{a}^{\mathrm{s}}{ }_{\mathrm{k}}$ realization, can be implemented measuring transport performances (transport monitoring) (Figure 4). 


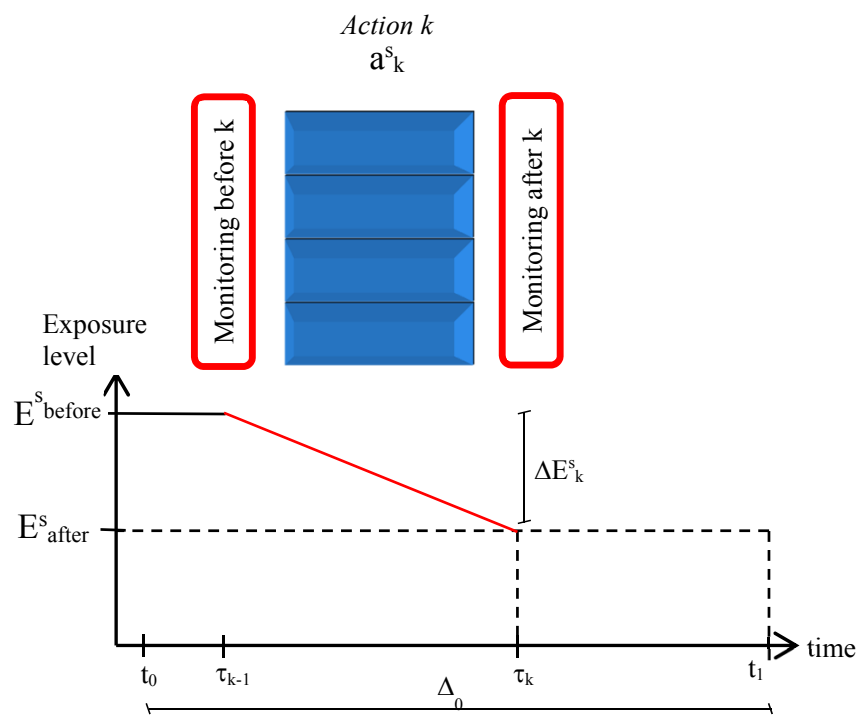

Figure 4: Exposure reduction related to training action $\mathrm{k}$.

\section{References}

[1] United Nations, UNISDR counts the cost of 20 years of inaction on climate change and risk reduction, 2012, http://www.unisdr.org/files/ 27162_2012no21.pdf (last access, June 2014).

[2] United Nations, Hyogo framework for action 2005-2015. Building the Resilience of Nations and Communities to Disasters. Mid-Term Review 2010-2011，2011, http://www.unisdr.org/files/18197_midterm.pdf (last access, June 2014).

[3] Russo, F. \& Vitetta, A., Risk evaluation in a transportation system. International Journal of Sustainable Development and Planning, 1 (2), pp. 170-191, 2006.

[4] Lim, H. J., Lim, B. \& Piantanakulchai, M., A review of recent studies on flood evacuation planning. Proc. of the Eastern Asia Society for Transportation Studies, 9, 2013.

[5] Russo, F. \& Rindone, C., Planning in road evacuation: classification of exogenous activities. WIT Transactions on the Built Environment, 116, pp. 639-651, 2011.

[6] Russo, F., Rindone, C. \& Trecozzi M.R., The role of training in evacuation. WIT transactions on information and communication technologies, 44, pp. 491-502, 2012.

[7] Russo, F. \& Rindone, C., Civil risk manager at European level, WIT Transactions on Ecology and the Environment, 173, pp. 765-778, 2013.

[8] Muttarak, R. \& Pothisiri W., The role of education on disaster preparedness: case study of 2012, Indian Ocean earthquakes on Thailand's Andaman 
Coast. Ecology and Society 18(4): 51, 2013. http://dx.doi.org /10.5751/ES06101-180451.

[9] USA, DHS, FEMA, Homeland Security Exercise and Evaluation Program (HSEEP), 2013a. https:// hseep.dhs.gov/ pages/ 1001_HSEEP7.aspx, (last access April, 2014).

[10] USA, DHS, FEMA, Exercise Evaluation Guides, 2014b https://www.llis.dhs.gov/hseep (last access April, 2014).

[11] USA, DHS, FEMA, National Preparedness Goal, 2011 http://www.fema.gov/media-library-data/20130726-1828-25045-9470/ national_preparedness_goal_2011.pdf (last access June, 2014).

[12] USA, DHS, FEMA, Department of Homeland Security, Homeland Security Exercise and Evaluation Program (HSEEP), 2007 https:// hseep.dhs.gov/ pages/ 1001_HSEEP7.aspx, (last access December, 2012).

[13] USA, DHS, FEMA, Threat and Hazard Identification and Risk Assessment Guide. Comprehensive Preparedness Guide (CPG) 201, edition 2013, 2013b, http://www.fema.gov/media-library-data/8ca0a9e54dc8b037 a55b402 b2a269e94/CPG201_htirag_2nd_edition.pdf, (last access April, 2014).

[14] Council of the European Union, Council decision of 8 November 2007 establishing a Community Civil Protection Mechanism (recast) (2007/779/EC, Euratom), 2007, http://eurlex.europa.eu/LexUriServ/ LexUriServ.do?uri=OJ:L:2007:314:0009:0019:EN:PDF (last access, April 2014).

[15] EC, European Commission, Report from the commission to the European parliament and to the council. Annual Report on the European Union's Humanitarian Aid and Civil Protection Policies and their Implementation in 2012. $\operatorname{COM}(2013) \quad 658, \quad 2013$, http://ec.europa.eu/echo/files/media/ publications/annual_report/2012/COM_2013_658_en.pdf.

[16] EC, European Commission, The European Civil Protection Training Programme, $2012 \mathrm{http} / /$ ec.europa.eu/echo/civil_protection/civil/prote /pdfdocs/Training\%20brochure.pdf, (last access April 2014).

[17] Council of the European Union, Decision no 1313/2013/EU of the European Parliament and of the Council of 17 December 2013 on a Union Civil Protection Mechanism, 2013, http://eur-lex.europa.eu/LexUriServ /LexUriServ.do?uri=OJ:L:2007:314:0009:0019:EN:PDF (last access, April 2014).

[18] EC, European Commission, Civil Protection Financial Instrument. Call for proposals 2014 for prevention and preparedness projects in the field of civil protection and marine pollution, 2014a, http://ec.europa.eu/echo/funding /opportunities/calls/2014_call_prevprep_cp_marine_pol_en.htm.

[19] EC, European Commission. Union Civil Protection Mechanism Exercises, 2014b. http://ec.europa.eu/echo/funding/opportunities/calls/2014_call_CP_ Mechanism_Exercises_en.htm (last access, May 2014).

[20] EC, European Commission, Commission decision of 29 December 2003 laying down rules for the implementation of Council Decision 2001/792/EC, Euratom establishing a Community mechanism to facilitate 
reinforced cooperation in civil protection assistance interventions. 2004/277/EC, Euratom, 2003.

[21] EC, European Commission. Civil Protection Work Programme. Information Day 2014, 2014c, http://ec.europa.eu/echo/funding/ financial_instrument_en.htm (last access, May 2014).

[22] Russo, F. \& Chilà, G., Integrated travel demand models for evacuations: a bridge between social science and engineering. International Journal of Safety and Security Engineering, 4 (1), pp. 19-37, 2014.

[23] Polimeni, A. \& Vitetta, A., Joint network and route optimization in road evacuation. WIT Transactions on Ecology and the Environment, 155, pp. 1053-1065, 2011.

[24] Marcianò, F.A., Musolino, G. \& Vitetta, A., Within-day traffic assignment and signal setting in road evacuation: A procedure with explicit path enumeration. WIT Transactions on the Built Environment, 117, pp. 403414, 2011.

[25] CCPS. Center for chemical process safety. Guidelines for developing quantitative safety risk criteria. Wiley and Sons. Ed., New York, 2009. 